\title{
1 Effects of using Recycled Concrete Aggregates on the shrinkage of High
}

\section{Performance Concrete}

Andreu Gonzalez-Corominas ${ }^{1}$, Miren Etxeberria ${ }^{1} *$

\footnotetext{
${ }^{1}$ Department of Construction Engineering, Polytechnic University of Catalonia, Jordi Girona, 1-3 B1 building, Barcelona 08034, Spain.

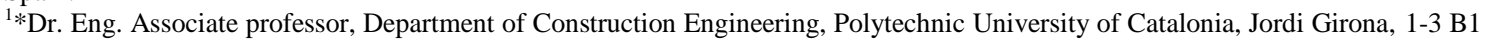
building, Barcelona 08034, Spain, telephone: +34934011788, Fax: +34934017262, E-mail: miren.etxeberria@upc.edu
}

Keywords: recycled aggregate, high performance concrete, plastic shrinkage, autogenous shrinkage, drying shrinkage.

\section{Abstract}

Over the past twenty years the use of Recycled Concrete Aggregate (RCA) has been mostly limited to normal-strength concretes. However, satisfactory properties have been found in previous studies dealing with the use of RCA sourced from medium to high strength concrete in the production of High Performance Concrete (HPC). In this study the effects of RCA were investigated in the plastic, autogenous and drying shrinkage of HPC. The quality of the RCA (sourced from concretes of 100, 60 and $40 \mathrm{MPa})$ and the replacement ratio $(20,50$ and $100 \%)$ were assessed. The results revealed that the plastic and drying shrinkage became higher as the quality of the RCA decreased and the replacement ratio increased. However, a reduction in the autogenous shrinkage was proved to be possible by the employment of a higher content of lower quality RCA, as this, in fact, acted as internal curing agent. The effects of the internal curing explained the similar or higher compressive strength results of concretes containing RCA when compared to those obtained from the reference concrete.

\section{Introduction}

Over the last twenty years Recycling Construction and Demolition Waste (C\&DW) has become a main economic and environmental concern for governments and public institutions. According to the Eurostat [1] C\&DW represents the most voluminous waste stream in Europe. Consequently, standards and directive frameworks have been published in order to bring about the control and reduction of C\&DW disposal in landfills, decrease the disposal site growth and promote the conservation of natural resources. 
In general, when compared to natural aggregates, Recycled Concrete Aggregates (RCA) sourced from C\&DW have the following differences in properties, lower density, crushing resistance and fragmentation resistance, and higher water absorption and porosity (the latter due to the old mortar attached to the aggregates) [2,3]. Many studies have focused on the physical, mechanical and durability properties of concrete employing recycled aggregates [4-15] and their findings have concluded that when compared with natural aggregates the lower properties of the recycled aggregates have a detrimental effect on the physical, mechanical and durability properties of the Recycled Aggregate Concrete (RAC). However, the use of RCA has successfully developed since its initial use via the strict following of minimum qualities, maximum replacement ratios, particular mixing methods or mixing designs using mineral admixtures $[2,10,14,16-20]$

Nevertheless, only a few studies have focused on the effects of using recycled aggregates in High Performance Concrete (HPC) [21-26]. HPC is designed to have more desired workability, higher compressive strength and improved durability properties than those of traditional concrete [27]. autogenous shrinkage [28,29].

The shrinkage phenomenon is defined as the volume reduction or strain due to the water loss by evaporation through the concrete surface or via the reactions of cement hydration [30,31]. Total shrinkage is made up of plastic shrinkage, autogenous shrinkage and drying-shrinkage and is the consequence of diverse factors such as temperature and relative humidity, size and shape of the concrete piece, components, water/binder ratios and age of concrete [18].

Plastic shrinkage occurs prior to the setting time of concrete as a result of water evaporation or suction, resulting mainly in the production of cracking on the surface layers [30]. Autogenous shrinkage, however, is caused by capillary depression during $\mathrm{CSH}$ formation as a result of the combination of water and 
ratios and higher binder amounts, which lead to greater self-desiccation and higher internal stress [28]. Autogenous shrinkage can be significantly reduced or even eliminated via the use of lightweight aggregates and recycled ceramic/masonry aggregates [28,29,32,33].

The drying shrinkage occurs when the free water stored in the capillary pores evaporates due to a low relative-humidity environment. This circumstance leads to a humidity gradient which induces the transport of water particles from the calcium silicate hydrates ( $\mathrm{CSH})$ to the capillary pores after which it evaporates [30]. Drying shrinkage produces internal stress, mass loss and consequently volume reduction of the concrete.

The study of Silva et al. [34], which reviewed the influence of recycled aggregates on the drying shrinkage, found that RAC usually exhibits higher shrinkage than the corresponding NAC. However, low replacement levels of natural aggregates by RCA, up to 30\%, showed similar or slightly higher shrinkage values than those of NAC [35-37]. According to the mentioned studies, the HPC produced employing any percentage of RCA suffered a greater drying shrinkage than those of concretes produced with natural aggregates [21-23].

In this research work, the influence of using recycled concrete aggregates (RCA) on the plastic, autogenous and drying shrinkage of High Performance concrete (HPC) was analysed. Three different types of RCA, in relation to their parent concrete's strength, were used. Three replacement ratios $(20,50$ and $100 \%$ ) were also chosen for each type of RCA to substitute the coarse natural aggregates in order to study the influence of the quality and amount of RCA in the HPC.

\section{Experimental details}

\subsection{Materials}

\subsubsection{Cement and admixture}

The cement used in the HPC production was a commercially available Portland cement (CEM I 52.5R) equivalent to ASTM Type I cement. The Blaine specific surface and density of the Portland cement were $4947.8 \mathrm{~cm}^{2} / \mathrm{g}$ and $3.15 \mathrm{~g} / \mathrm{cm}^{3}$, respectively, and its chemical composition is given in Table 1. A rapid 
hardening Portland cement was employed in order to achieve 1-day compressive strengths higher than 50 $\mathrm{MPa}$, thus fulfilling the minimum requirements to be used in precast and prestressed concrete [38,39].

The admixture selected for the concrete production was a high performance superplasticizer based on modified polycarboxylate-ether (PCE). The specific gravity of the admixture was 1.08.

\subsubsection{Aggregates}

The source and type of the natural aggregates used in the production of the concrete were the same as those used in previous studies [24,25] and are those presently used in the production of a commercial High Performance Concrete in a Spanish precast concrete company. The natural fine aggregates employed were two river sands which were mainly composed of silicates divided into two different particle size fractions $(0-2 \mathrm{~mm}$ and $0-4 \mathrm{~mm})$ in order to achieve higher compaction. Two types of coarse natural aggregates were used to improve the workability and the mechanical behaviour of the concrete, rounded river gravel (siliceous composition) and crushed dolomitic coarse aggregate. The physical and mechanical properties of the natural aggregates are given in Table 2.

The three coarse RCAs were sourced from crushing parent concretes of different qualities, whose characteristic compressive strengths after 28 days were 100, 60 and 40MPa. The RCAs were crushed and sieved to achieve similar particle size distributions to those of the coarse natural aggregates. The physical properties of the RCAs are also shown in Table 2 (coded as RCA-X, $\mathrm{X}$ according to their compressive strength).

In comparison with coarse recycled concrete aggregates, natural aggregates have a higher density and lower water-absorption capacity, a fact which has been reported in several studies $[2,3,40]$. However, it has been found that when the quality of the original concrete increased, the physical properties of the RCA also improved $[8,41,42]$. Likewise, the mechanical properties of the RCA were directly related to the compressive strength of the parent concrete $[41,43]$. The crushing resistance values obtained by RCA were lower than those obtained by both natural aggregates. The fragmentation coefficients were consistent to those presented by Silva et al. [2]. As was expected, their considerably low values were a result of the high qualities of the parent concretes.

The soluble sulphate $(0.43-0.52 \%)$ and the chloride content $(0.01-0.02)$ of the RCAs fulfilled the maximum requirements of 0.8 and $0.03 \%$, respectively, established by the Spanish structural concrete code [44] for prestressed elements. 


\subsection{Concrete mixtures}

115 All concrete mixtures were prepared and produced in the laboratory. As shown in the concretes 116 proportioning in Table 3 . The $380 \mathrm{~kg}$ cement quantity and effective water/cement ratio of 0.29 were kept constant in all concrete productions (considering effective water as that amount water reacting with the binder or not stored in the aggregates [30]). The recycled aggregates were used as 0, 20, 50 and $100 \%$ by volume replacement of both coarse natural aggregates.

The NAC proportioning, which was provided by a Spanish precast concrete company, was based on the Fuller dosage method [45]. The concrete proportioning parabola was in accordance with the Gessner parabola provided by the Fuller method in both cases, whether using NA or RCA aggregates. The recycled aggregate concretes, referenced as R-X-Y (X indicating the quality of the RCA and Y indicating the replacement ratio) had a constant cement amount and admixture content (1.5\% of the cement weight).

The results from the concrete slump test (UNE-EN 12350-2:2009) using the Abrams cone were dry consistencies of 0-20 mm (S1 class following the BS-EN 206-1:2000). The natural aggregate concrete mixture, which was considered as the reference concrete, replicated the High Performance Concrete mixture used by an existing precast concrete manufacturer. The reference HPC had low water-cement ratio and very low workability in accordance with the design requirements stipulated for the technical requirements of prestressed concrete sleepers [38]. With regards to prestressed concrete elements the main requirement for those mixtures is the high early compressive strength (minimum of $50 \mathrm{MPa}$ after 24 hours $[38,39])$, in order to bear the tension release from the prestressing wires. However the workability of the concretes mixtures is a minor concern for prestressed concrete manufacturer due to the automated process of concrete pouring and high-intensity vibrating-table for compaction.

All RCAs were used at $80-90 \%$ saturation at the moment of concrete production. Additional water was added at mixing time to compensate for the remaining water absorption of the RCAs, thus maintaining constant the effective water-cement ratio. Results revealed that the total water amount of the recycled aggregate concretes increased with the reduced quality of the RCA employed, the reason for this being the recycled aggregates higher water absorption capacity (see Table 2). The total amount of water was considered as the amount of effective water together with the absorbed water of the aggregates [30]. 


\subsubsection{Physical and mechanical properties}

The physical (dry-density, water absorption and accessible voids) and mechanical properties (compressive strength and modulus of elasticity) were tested in order to characterize the hardened concrete produced. The dry-density, water absorption and percentage of accessible voids at 28 days (ASTM C 642-13) and the compressive strength at 1, 28 and 90 days (UNE-EN 12390-3:2009) were tested via the use of a cubic specimen of $100 \times 100 \times 100 \mathrm{~mm}$. The testing of the modulus of elasticity at 28 days was conducted via the use of cylindrical specimens of 200x100 $\varnothing \mathrm{mm}$ following UNE-EN 1239013:2014 specifications.

\subsubsection{Pore size distribution}

The testing of porosity and pore structure was performed by Mercury Intrusion Porosimetry (MIP) with a 'Micromeritics Poresizer 9320' mercury intrusion porosimeter, following BS7591 Part 1. This test was carried out on small concrete samples weighing approximately $5.5 \mathrm{~g}$. The crushed samples were obtained from the $100 \times 100 \times 100 \mathrm{~mm}$ cubic specimens. The samples were first immersed in acetone for 4 days to stop the cement hydration and then introduced in a vacuum drier for 2 hours, in order to extract the remaining acetone. Before testing, the samples were dried in an oven at $50^{\circ} \mathrm{C}$ for 4 days. The MIP test was conducted on the concrete samples cured at ages 1, 28 and 90 days and each result is the average of the three tested samples. The pore size distribution, total porosity and average pore size were obtained from the MIP tests.

\subsubsection{Plastic shrinkage}

The setup for the plastic shrinkage test was based on a previous study by Saliba et al. [46]. The plastic shrinkage strain was measured with LVDTs which were connected to a data acquisition system. The LVDTs' length of charge was recorded every minute for 12 hours after concrete casting. The steel mould used in this experiment was a square prism of $600 \times 150 \times 150 \mathrm{~mm}$ covered with Teflon sheeting. One side of the concrete specimen was embedded in the mould while the other side was left exposed to a freemoving Teflon plate via the use of 4 steel rebars $(\varnothing 10 \mathrm{~mm})$ in each side (see Fig. 1). The LVDT was setup on the mould's remaining steel plate and it was in direct contact with the free-moving Teflon plate. 
The taking of plastic strain measurements started immediately after concrete casting, in order to record all the linear length changes up to the setting time. The test specimens were kept under the same conditions of $23 \pm 2{ }^{\circ} \mathrm{C}$ of temperature and $50 \pm 5 \%$ relative humidity for the entire test period. Two specimens from each concrete mixture were tested and the mean value was reported.

\subsubsection{Autogenous shrinkage}

Autogenous shrinkage strain measurements were conducted following the recommendations of the Japan Concrete Institute (JCI) [47]. Strain gauges were vertically embedded in the centre of the specimens using cylindrical moulds of $300 \times 150 \varnothing \mathrm{mm}$. After casting, the free upper surfaces of the moulds were immediately covered with two layers of adhesive aluminium foil in order to prevent moisture loss from the concrete specimen. The strain gauges were connected to a data acquisition system within the first 10 minutes after the concrete casting and the strain measurements recorded. The concrete specimens were de-moulded 1 day after casting and entirely wrapped in two layers of adhesive aluminium foil, thus preventing them from suffering from inner water evaporation. In order to ensure continuous measurements, readings were taken at 1 min intervals for 3 days in two replicate specimens per concrete mixture. The specimens were kept sealed and stored in a climatic chamber under the same environmental conditions (temperature of $23 \pm 2{ }^{\circ} \mathrm{C}$ and $50 \pm 5 \%$ relative humidity) throughout the whole measurement period.

\subsubsection{Drying shrinkage}

The drying shrinkage of concretes was determined in accordance with the procedure laid out in ASTM C596 (2009) using $70 \times 70 \times 285$ mm prismatic specimens. Each specimen was fitted with a stainless steel stud at both ends. The prismatic specimens were covered with a wet burlap and a plastic sheet during the initial 24 hours before being removed from the moulds and then cured under water for an additional period of 48 hours. At the age of three days, the specimens were removed from the water tank and wiped with a damp cloth. The initial length reading and the initial mass were immediately recorded using a length comparator and a scale, respectively. Then the specimens were placed in an environmental room at a controlled temperature of $23 \pm 2{ }^{\circ} \mathrm{C}$ and $50 \pm 5 \%$ relative humidity for one year. The drying shrinkage was determined by taking measurements at 1, 4, 7, 14, 21, 28, 56, 90, 180, 360 days and each result was the average obtained from the testing of three specimens per concrete mixture. 


\section{Results and discussion}

\subsection{Physical and mechanical properties}

The test results on the physical and mechanical properties of natural and recycled aggregate concretes can be observed in Table 4 . As mentioned in previous studies [24,25], the dry-density decreased and the water absorption and accessible voids percentage increased as the quality of the recycled aggregates was reduced. Furthermore, the increase in the replacement ratio had negative effects on the physical properties of the recycled aggregates. The modulus of elasticity was also linearly affected by the RCA quality reduction and the increase of the replacement ratios, as were to the physical properties. However, on assessing the compressive strength it was observed that the results between NAC and RAC containing up $100 \%$ of RCA100 and up to $50 \%$ of RCA60 and RCA40 were similar. The compressive strength of RAC was the least influenced by the quality and the amount of RCA than any other property. At longer ages, up to 90 days, the recycled aggregate concretes exhibited higher compressive strength gains than those of the NAC. The improved Interfacial Transition Zone (ITZ) $[8,14]$ and the internal curing $[29,35]$ could be responsible for the enhancement of the mechanical performance of HPC employing recycled aggregates.

\subsection{Pore size distribution}

Pore size distributions of concrete samples were determined for NAC and RAC containing 100\% of RCA and their results can be observed in Figs. 2a-c. Moreover, the MIP test was employed to determine the porosity and the average pore size of each concrete mixture (see Table 5). The MIP tests were carried out at 1,28 and 90 days of curing.

After 1 day of curing, the concrete mixture produced with RCA100 showed significant lower porosity, lower average pore size and lower pores at any size range than those of NAC (See Fig 2a and Table 5). In NAC, the porosity is higher in the aggregate-paste interface than in the paste itself and the pore size is usually larger $[48,49]$. Nevertheless, the ITZ is improved by the use of recycled aggregates as certain authors have pointed out [14] which could explain the reduction on the porosity of RAC100-100. Nevertheless, RAC containing lower quality RCA which had a higher total water-cement ratios resulted in the worsening of porosities, average pore sizes and pore size distributions at very early ages.

Fig. $2 \mathrm{~b}$ shows that the pore size distributions of RAC100-100 and RAC60-100, at 28 days of age, were similar to those of NAC, which obtained the lowest pore volumes. Only the RAC produced with the 
lower quality aggregate (RCA40) had significant higher capillary pore volumes than NAC. The porosity and average pore sizes also showed higher increases as the quality of RCAs decreases.

After 90 days of curing, the RACs containing RCA40 and RCA60 showed the highest improvements of porosity and pore size distributions. The RCA40 and RCA60 could act as internal curing agents, producing an extension of the binder hydration, found to be especially useful in HPC [29,35]. Internal curing in HPC leads to lower internal stress and also enhances cement matrix densification [32]. Furthermore, the pore distribution of RAC100-100 kept similar pore structures to those of NAC due to the presence of the old-mortar attached to the RCA which had the same quality as the new mortar.

\subsection{Plastic shrinkage}

The development of plastic shrinkage up to 12 hours is shown in Figs. 3a-c. The highest plastic shrinkage strain recorded was that of the concretes produced with low quality recycled aggregates, up to $-600 \mu \varepsilon$. Although there exists an abundant variety of information concerning the testing procedures for measuring plastic shrinkage, a review of that literature revealed in the main higher plastic shrinkage values than those found in our studies [46,50,51].

Throughout the entire testing period, the plastic shrinkage of the concrete mixtures produced with any type of RCA was higher than those produced with NAC. However, the plastic shrinkage of the concrete mixtures made with RCA derived from original concrete with higher strength values was lower than that of concretes prepared with RCA derived from lower strength parent concretes. In concrete with $100 \%$ of RCA (Fig. 3a), R100 had a 130\% higher plastic shrinkage than that of NAC after 12 hours of age. The R60 and R40 (Figs 3b and 3c, respectively) suffered an average increase of $200 \%$ shrinkage in comparison with NAC when using $100 \%$ RCA.

Similarly, the increase in the amount of RCA had a negative influence on the plastic shrinkage. While the concrete mixtures with a $20 \%$ RCA replacement ratio showed plastic shrinkage increases of $46-152 \%$ in comparison with those of NAC, the 50\% and the $100 \%$ RCA replacement ratios produced $65-150 \%$ and 130-208\% increases of plastic shrinkage, respectively. The rate of plastic shrinkage is highly dependent on the water-to-binder ratio [46,51]. The RACs contain a higher total water-cement ratio which in the initial stages of curing results in a higher effective water content. However, the additional water added to the mix to compensate for the RCA's remaining water absorption effectively caused in time a higher plastic shrinkage. The higher the RCAs' w/c ratio, then the higher the plastic shrinkage values achieved. 
These values being a direct result of the RCAs', not only having a higher relative humidity but also a larger porous networks at an early age, which facilitates rapid water evaporation [46].

Plastic shrinkage cracking spreads when the surface tension increases as a cause of the evaporation of superficial water which effectively increases the capillary pore stress [52]. However, plastic shrinkage strain is reduced when the evaporated water in the binder composite is replaced by bleeding water [53]. The findings of certain studies have determined that highly porous aggregates, such as Lightweight Aggregates (LWA) [54,55] or Mixed Recycled Aggregates [56], can act as internal curing agents and provide water to reduce very early shrinkage. The RCA aggregates which have lower water absorption capacity and smaller pore networks than LWA and MRA aggregates proved to be ineffective in the reduction of the plastic shrinkage.

However, the plastic shrinkage strains found in the laboratory proved to be significantly lower than those proposed by Baghabra et al. [50], whose threshold value of plastic shrinkage strain was established as $1100 \mu \varepsilon$, above which there is a high risk of cracking occurring. Moreover, Won et al. [53] observed through an analysis of his studies that there was no plastic shrinkage cracking occurrence in any of the high-strength concrete mixtures tested under restrain conditions. Consequently, it is highly improbable that the RAC mixtures produced in this study would suffer from plastic shrinkage cracking.

\subsection{Autogenous shrinkage}

As previously mentioned, the autogenous strain test was performed on sealed concrete specimens immediately (approximately $10 \mathrm{~min}$ ) after casting, minute by minute measurements being continuously taken and recorded. Figs. $4 a-c$ presents the results from testing the autogenous shrinkage up to 72 hours for NAC and RAC mixtures.

The concrete mixtures produced employing natural aggregates and RCA100 were subjected to an immediate measurement of the autogenous shrinkage after casting, in order to determine and register autogenous shrinkage strain. Certain studies [28,29] revealed an initial non-shrinking or dormant stage in the preliminary hours of concrete mixture setting, however, this phenomenon did not occur in the concrete mixtures tested within this study. The use of rapid-hardening cement could be responsible for the reduction of this dormant period in our test findings, as rapid-hardening cement contains a higher amount of $\mathrm{C}_{3} \mathrm{~S}$ and finer grinding, which could have the effect of reducing both the layer and barrier effects that produce the dormant period [30,31]. 
However, it was found that the concrete mixtures produced using RCA60 and RCA40 swelled slightly from the initiation of the testing period up to 2.5 hours after casting. A fact mentioned in other studies dealing with the use of recycled aggregates [28,29]. The maximum expansions registered were $5-27 \mu \varepsilon$ which were considerably lower than the expansion values found by Meddah et al. [28] and Suzuki et al. [29] for concretes containing ceramic aggregates. The higher porosity and higher pore interconnection found in ceramic aggregates facilitates a much quicker and easier transfer of water to the paste than in RAC aggregates.

The autogenous shrinkage starts as the cement hydration reactions consume the water from the capillary pores [30,31]. The formation of capillary-water menisci and the increase of capillary-tension produce the capillary volume reduction which establishes the autogenous shrinkage [28]. The autogenous shrinkage started immediately after casting in the NAC, RAC-100 (at any replacement ratio) and RAC-60-20 concretes. There was a very significant increase in the autogenous shrinkage for the firsts 10-12 hours, reaching almost total development. The autogenous shrinkage of any of the concretes under study was at the point of stabilization after 3 days. The RAC-100 concrete (at any replacement ratios) and RAC-60-20 showed similar or slightly lower autogenous shrinkage than that of the NAC.

The reduction in the quality of the RCA aggregates and the increase in their replacement ratios improved behaviour of the RAC-60 and RAC-40 concretes with 50 to $100 \%$ replacement ratios was slightly different to that of the NAC. The concretes produced with a higher percentage of RCA suffered lower autogenous shrinkage as a result of the higher amount of water storage within the aggregates. Almost all of the autogenous shrinkage had developed within the 8-10 hours after commencing testing. As Figs.4b and $4 \mathrm{c}$ clearly indicate, determined that after 72 hours of commencing continuous testing, the RAC concrete produced employing $100 \%$ of RCA60 and RCA40 achieved reductions of $82 \%$ and $73 \%$, respectively, with respect to the NAC concrete's autogenous shrinkage. Additionally, the obtained strain values of the mentioned concretes proved to be below that of $-50 \mu \varepsilon$, as a consequence of which these concrete mixtures could be almost considered as non-shrinking concretes.

As certain studies employing lightweight aggregates and recycled ceramic aggregates have pointed out

$310[28,29,33]$, the saturated aggregates act as water reservoirs thus reducing or even eliminating the 
the transportation of water from the RCA pores to the new cement paste via capillarity. As the quality of the RCA is reduced, the pore size distribution of the old cement paste increases [57] thus easing the capillary water transportation to the new cement paste. The water streaming reduces the formation of menisci and lowers the internal capillary tension that produce the development of autogenous shrinkage. This mechanism is also beneficial for the mechanical properties as it acts as internal curing which extends the cement hydration and increases long-term compressive strength gain $[29,32,33,58]$.

\subsection{Drying shrinkage}

Figs. 5a-c show the results of drying shrinkage obtained up to 1 year. After 90 days, the strains caused by drying shrinkage ranged from -311 to $-717 \mu \varepsilon$. Such results are in line with those results determined by several other authors employing_RCA aggregates [16,23,59], as are the typical drying-shrinkage values described by the ACI [60] (-200 to $-800 \mu \varepsilon)$.

In natural aggregate concrete, the higher the w/c ratio, the greater the amount of shrinkage within the concrete [30,32]. However, in concretes containing highly porous aggregates, the water contained within these aggregates also plays an important role in the amount of shrinkage increase [32,61,62]. The relationship between the RCA replacement ratio and drying shrinkage strain represented in Fig. 6 shows a solid linear correlation for each quality of RCA. The Pearson's $r$ linear correlation coefficients were in a range of $0.92-0.99$ and the linear regressions had $\mathrm{R}^{2}$ of $0.86-0.99$. The highest drying shrinkages occurred in those concretes containing the highest RCA replacement ratios and the lowest RCA qualities. Consequently, the influence of the RCA aggregates was lower when using the highest quality aggregates (RCA100), agreeing with the findings on the matter of both Kou and Poon [23].

The concretes produced using RCA100 achieved 54-56\% higher shrinkage levels than those of NAC at 28 days of testing. The shrinkage strain increased significantly when the concretes were produced using RCA60 and RCA40. At 28 days of testing, the shrinkage strain of R60 and R40 concrete mixtures were $50-113 \%$ and $57-172 \%$ higher, respectively than those of NAC. The maximum shrinkage corresponding to $100 \%$ replacement of natural aggregates for RCA aggregates. Nevertheless, it was found that the drying shrinkage of all concretes was established after 90 days of testing.

The negative influence of RCA on the drying shrinkage when HPC concretes were produced employing the highest quality recycled aggregates (RCA100) was similar to that found in other studies [23,62]. However, concretes produced using a lower quality recycled aggregates (RCA60 and RCA40) revealed 
higher increases in the drying shrinkage of the HPC concrete. One can only consider that the water-tocement ratio of the concretes produced and analysed in this study was lower than those produced by Domingo-Cabo et al. [62] and Kou and Poon [23]. Consequently, producing higher difference between the quality of the new concrete and the quality of the RCA aggregates than they determined in their studies.

The higher amount of cement paste (taking into consideration both the old and new paste) contained in the RAC concrete is the cause of the production of the higher concrete porosity. Moreover, the use of presoaked RCA aggregates in the production of RAC concrete, in order to facilitate the proper workability of the fresh concrete, means that there is more water available for evaporation. As shown in Figs. 7a-c, the concretes containing higher amounts of RCA and lower quality RCA were the concretes that had the highest mass losses. These losses directly corresponding to the amount of water evaporated. The water evaporation grew faster and greater as the RCA amount employed increased and the quality decreased. An analysis of test results leading to conclusions similarly to the observations made by Zhutovsky and Kovler [32] in mixes containing lightweight aggregates.

It is widely known that the aggregate's stiffness has a great influence on shrinkage restraint and that a higher aggregate-cement ratio also lowers the shrinkage within the concrete [30]. According to Silva et al. [34], the concretes produced employing less stiff recycled aggregates achieved a lower modulus of elasticity consequently a greater shrinkage within the concrete. Fig. 8 shows the relationship between the recycled aggregate concretes' relative modulus of elasticity (in comparison with that of NAC) and the drying shrinkage after 28 days. The results confirmed that the RAC's modulus of elasticity, which is dependent on the elastic modulus of the coarse aggregate [63], has a significant effect on the drying shrinkage. The relationship between the concrete's relative modulus of elasticity and drying shrinkage strain depicted in Fig. 8 is in accordance with the findings presented by Silva et al. [34] and it also shows a strong linear correlation. The Pearson's $\mathrm{r}$ linear correlation coefficient was -0.95 and the linear regression had a $\mathrm{R}^{2}$ of 0.90 .

\section{Conclusions}

The following conclusions can be made based on the results of this study: 
- The dry-density and the modulus of elasticity of HPC produced with recycled aggregates decreased and the water absorption and the porosity increased when the quality of the RCA employed was reduced and their replacement ratio was increased.

- The compressive strength of HPC produced using $100 \%$ of RCA100 and up to 50\% of RCA60

\section{Acknowledgements} and RCA40 recycled aggregates showed similar values to those of NAC. Moreover, a greater enhancement of compressive strength was shown in HPC using RCA.

- $\quad$ The RACs showed higher improvements of porosity and pore size distributions than those from NAC. The particle size distributions of NAC and concretes containing $100 \%$ of RCA100 and RCA60 were very similar after 90 days.

- The plastic shrinkage of concretes increased as the employed RCA quality was reduced and the replacement ratio was increased. However the obtained values for all HPC concretes were lower than those required with respect to concrete cracking.

- The autogenous shrinkage of concretes decreased as the quality of RCA employed was reduced and their replacement ratio increased. This was probably due to a higher water storage capacity of RCA.

- The lower quality of the RCA aggregates employed as well as higher replacement ratios had the effect of producing the highest test values of drying shrinkage within the concrete. A downward linear trend was confirmed with respect to both a decrease in the relation of the modulus of elasticity of the RAC's and NAC's and an increase of drying shrinkage

The concretes produced using $100 \%$ of RCA aggregates (originating from the same quality as the new HPC) and the concretes produced using $50 \%$ of lower quality RCA (produced crushing concretes with up to $40 \mathrm{MPa}$ of compressive strength) from the mechanical and shrinkage point of view could be employed in the production of HPC, as they achieved similar or better properties than those produced with natural aggregates.

The authors wish to acknowledge the financial support of The Ministry of Economy and Competitiveness by INNPACT Project (IPT-2011-1655-370000).

\section{References}

[1] Eurostat. Waste statistics in Europe 2012. 
[2] Silva RV, de Brito J, Dhir RK. Properties and composition of recycled aggregates from construction and demolition waste suitable for concrete production. Constr Build Mater 2014;65:201-17.

[3] Agrela F, Sánchez de Juan M, Ayuso J, Geraldes VL, Jiménez JR. Limiting properties in the characterisation of mixed recycled aggregates for use in the manufacture of concrete. Constr Build Mater 2011;25:3950-5.

[4] Xiao J, Li W, Fan Y, Huang X. An overview of study on recycled aggregate concrete in China (1996-2011). Constr Build Mater 2012;31:364-83.

[5] Thomas C, Setién J, Polanco J a., Alaejos P, Sánchez de Juan M. Durability of recycled aggregate concrete. Constr Build Mater 2013;40:1054-65.

[6] Tabsh SW, Abdelfatah AS. Influence of recycled concrete aggregates on strength properties of concrete. Constr Build Mater 2009;23:1163-7.

[7] Poon CS, Shui ZH, Lam L, Fok H, Kou SC. Influence of moisture states of natural and recycled aggregates on the slump and compressive strength of concrete. Cem Concr Res 2004;34:31-6.

[8] Poon CS, Shui ZH, Lam L. Effect of microstructure of ITZ on compressive strength of concrete prepared with recycled aggregates. Constr Build Mater 2004;18:461-8.

[9] Kwan WH, Ramli M, Kam KJ, Sulieman MZ. Influence of the amount of recycled coarse aggregate in concrete design and durability properties. Constr Build Mater 2011;26:565-73.

[10] Kou SC, Poon CS, Etxeberria M. Influence of recycled aggregates on long term mechanical properties and pore size distribution of concrete. Cem Concr Compos 2011;33:286-91.

[11] Kou SC, Poon CS. Enhancing the durability properties of concrete prepared with coarse recycled aggregate. Constr Build Mater 2012;35:69-76.

[12] Koenders EAB, Pepe M, Martinelli E. Compressive strength and hydration processes of concrete with recycled aggregates. Cem Concr Res 2014;56:203-12.

[13] Etxeberria M, Vázquez E, Marí AR. Microstructure analysis of hardened recycled aggregate concrete. Mag Concr Res 2006;58:683-90.

[14] Etxeberria M, Vázquez E, Marí A, Barra M. Influence of amount of recycled coarse aggregates and production process on properties of recycled aggregate concrete. Cem Concr Res 2007;37:735-42.

[15] Etxeberria M, Gonzalez-Corominas A, Valero I. Application of low-grade recycled aggregates for non-structural concrete production in Barcelona city. Int. Conf. Sustain. Constr. Mater. Technol., Kyoto, Japan: Committees, SCMT3; n.d.

[16] Brand AS, Roesler JR, Salas A. Initial moisture and mixing effects on higher quality recycled coarse aggregate concrete. Constr Build Mater 2015;79:83-9.

[17] Tam VWY, Gao XF, Tam CM. Microstructural analysis of recycled aggregate concrete produced from two-stage mixing approach. Cem Concr Res 2005;35:1195-203.

[18] Tam VWY, Tam CM. Assessment of durability of recycled aggregate concrete produced by twostage mixing approach. J Mater Sci 2007;42:3592-602.

[19] Kou SC, Poon CS, Chan D. Influence of fly ash as a cement addition on the properties of recycled aggregate concrete. Mater Struct 2008;41:1191-201.

[20] Kou S, Poon C, Chan D. Properties of steam cured recycled aggregate fly ash concrete. In: Vázquez E, Hendriks C, Janssen G, editors. Int. RILEM Conf. use Recycl. Mater. Build. Struct., Barcelona, Spain: RILEM Publications SARL; 2004, p. 590-9.

[21] Ajdukiewicz A, Kliszczewicz A. Influence of recycled aggregates on mechanical properties of HS/HPC. Cem Concr Compos 2002;24:269-79.

[22] Limbachiya MC, Leelawat T, Dhir RK. Use of recycled concrete aggregate in high-strength concrete. Mater Struct 2000;33:574-80.

[23] Kou S, Poon C. Effect of the quality of parent concrete on the properties of high performance 
recycled aggregate concrete. Constr Build Mater 2015;77:501-8.

[24] Gonzalez-Corominas A, Etxeberria M. Experimental analysis of properties of high performance recycled aggregate concrete. Constr Build Mater 2014;52:227-35.

[25] Gonzalez-Corominas A, Etxeberria M. Properties of high performance concrete made with recycled fine ceramic and coarse mixed aggregates. Constr Build Mater 2014;68:618-26.

[26] Tu T-Y, Chen Y-Y, Hwang C-L. Properties of HPC with recycled aggregates. Cem Concr Res 2006;36:943-50.

[27] ACI Committee 363. State of the Art Report on High-Strength Concrete. Farmington Hills: 1997.

[28] Meddah MS, Sato R. Effect of curing methods on autogenous shrinkage and self-induced stress of high-performance concrete. ACI Mater J 2010;107:65-74.

[29] Suzuki M, Seddik Meddah M, Sato R. Use of porous ceramic waste aggregates for internal curing of high-performance concrete. Cem Concr Res 2009;39:373-81.

[30] Neville AM. Properties of Concrete. 4th ed. 1995.

[31] Hewlett P. Lea's Chemistry of Cement and Concrete. 4th ed. Butterworth-Heineman; 2004.

[32] Zhutovsky S, Kovler K. Effect of internal curing on durability-related properties of high performance concrete. Cem Concr Res 2012;42:20-6.

[33] Bentur A, Igarashi S, Kovler K. Prevention of autogenous shrinkage in high-strength concrete by internal curing using wet lightweight aggregates. Cem Concr Res 2001;31:1587-91.

[34] Silva RV, de Brito J, Dhir RK. Prediction of the shrinkage behavior of recycled aggregate concrete: A review. Constr Build Mater 2015;77:327-39.

[35] Corinaldesi V. Mechanical and elastic behaviour of concretes made of recycled-concrete coarse aggregates. Constr Build Mater 2010;24:1616-20.

[36] Yanagibashi K, Yonezawa T, Arakawa K, Yamada M. A new concrete recycling technique for coarse aggregate regeneration process. In: Dhir RK, Dyer TD, Halliday JE, editors. Proc. Int. Conf. Sustain. Concr. Constr., Scotland, UK: Thomas Telford; 2002, p. 511-22.

[37] Yang K-H, Chung H-S, Ashour AF. Influence of Type and Replacement Level of Recycled Aggregates on Concrete Properties. Mater J 2008;105:289-96.

[38] ADIF. Spanish Technical Specifications of Prestressed Concrete Monoblock Sleepers (ET 03.360.571.8 ). Madrid: 2009.

[39] Ramezanianpour AA, Khazali MH, Vosoughi P. Effect of steam curing cycles on strength and durability of SCC: A case study in precast concrete. Constr Build Mater 2013;49:807-13.

[40] Hansen TC. Recycling of demolished concrete and masonry. London (UK): E\&FN Spon; 1992.

[41] Nagataki S, Gokce A, Saeki T, Hisada M. Assessment of recycling process induced damage sensitivity of recycled concrete aggregates. Cem Concr Res 2004;34:965-71.

[42] Gokce A, Nagataki S, Saeki T, Hisada M. Identification of frost-susceptible recycled concrete aggregates for durability of concrete. Constr Build Mater 2011;25:2426-31.

[43] Padmini AK, Ramamurthy K, Mathews MS. Influence of parent concrete on the properties of recycled aggregate concrete. Constr Build Mater 2009;23:829-36.

[44] CPH-Comisión Permanente del Hormigón. Instrucción de Hormigón Estructural. EHE-08 (Spanish Concrete Structural Code) 2009.

[45] Fuller WB, Thompson SE. The laws of proportioniong concrete. Trans ASCE 1907;59:67-143.

[46] Saliba J, Rozière E, Grondin F, Loukili a. Influence of shrinkage-reducing admixtures on plastic and long-term shrinkage. Cem Concr Compos 2011;33:209-17.

[47] JCI Committee Report. Technical committee on autogenous shrinkage of Concrete. Autogenous shrinkage of concrete. Hiroshima, Japan: FN \& Spon; 1999. 
[48] Willis KL, Abell AB, Lange DA. Image-based characterization of cement pore structure using wood's metal intrusion. Cem Concr Res 1998;28:1695-705.

[49] Douglas N. Winslow MDC. Percolation and pore structure in mortars and concrete. Cem Concr Res 1994;24:25-37.

[50] Baghabra Al-Amoudi OS, Maslehuddin M, Abiola TO. Effect of type and dosage of silica fume on plastic shrinkage in concrete exposed to hot weather. Constr Build Mater 2004;18:737-43.

[51] Baghabra Al-Amoudi OS, Abiola TO, Maslehuddin M. Effect of superplasticizer on plastic shrinkage of plain and silica fume cement concretes. Constr Build Mater 2006;20:642-7.

[52] Mora-Ruacho J, Gettu R, Aguado A. Influence of shrinkage-reducing admixtures on the reduction of plastic shrinkage cracking in concrete. Cem Concr Res 2009;39:141-6.

[53] Won JP, Kim SH, Lee SJ, Choi SJ. Shrinkage and durability characteristics of eco-friendly fireproof high-strength concrete. Constr Build Mater 2013;40:753-62.

[54] Wyrzykowski M, Trtik P, Münch B, Weiss J, Vontobel P, Lura P. Plastic shrinkage of mortars with shrinkage reducing admixture and lightweight aggregates studied by neutron tomography. Cem Concr Res 2015;73:238-45.

[55] Corinaldesi V, Moriconi G. Use of synthetic fibers in self-compacting lightweight aggregate concretes. J Build Eng 2015;4:247-54.

[56] Etxeberria M, Gonzalez-Corominas A. Influence of sea water and blast furnace cement employment on recycled aggregate concretes' properties. Constr Build Mater 2015;Under Revi.

[57] Cook RA, Hover KC. Mercury porosimetry of hardened cement pastes. Cem Concr Res 1999;29:933-43.

[58] Corinaldesi V, Moriconi G. Recycling of rubble from building demolition for low-shrinkage concretes. Waste Manag 2010;30:655-9.

[59] Corinaldesi V, Moriconi G. Influence of mineral additions on the performance of $100 \%$ recycled aggregate concrete. Constr Build Mater 2009;23:2869-76.

[60] ACI Committee 209. Report on Factors Affecting Shrinkage and Creep of Hardened Concrete. Farmington Hills: 2005.

[61] Khatib JM. Properties of concrete incorporating fine recycled aggregate. Cem Concr Res 2005;35:763-9.

[62] Domingo-Cabo A, Lázaro C, López-Gayarre F, Serrano-López MA, Serna P, Castaño-Tabares JO. Creep and shrinkage of recycled aggregate concrete. Constr Build Mater 2009;23:2545-53.

[63] Lydon F., Balendran R. Some observations on elastic properties of plain concrete. Cem Concr Res 1986;16:314-24. 


\section{Click here to download Table: Tables_reviewed.docx}

\section{Tables:}

2 Table 1. Chemical composition of the Portland cement.

3 Table 2. Physical and mechanical properties of natural and recycled concrete aggregates.

4 Table 3. Proportioning of natural and recycled aggregate concretes.

5 Table 4. Physical and mechanical properties of hardened natural and recycled aggregate concretes.

6 Table 5. Porosity and average pore diameter from MIP test of natural aggregate concrete (NAC) and

7 recycled aggregate concretes containing $100 \%$ of RCA100, RCA60 and RCA40 at the ages of 1, 28 and 890 days.

9 


\begin{tabular}{|c|c|c|c|c|c|c|c|c|c|}
\hline Composition (\%) & $\mathrm{SiO}_{2}$ & $\mathrm{Al}_{2} \mathrm{O}_{3}$ & $\mathrm{Fe}_{2} \mathrm{O}_{3}$ & $\mathrm{CaO}$ & $\mathrm{MgO}$ & $\mathrm{K}_{2} \mathrm{O}$ & $\mathrm{Cl}$ & $\mathrm{SO}_{3}$ & LOI \\
\hline $\begin{array}{c}\text { Cement CEM I } \\
52.5 \mathrm{R}\end{array}$ & 21.75 & 3.38 & 4.55 & 64.65 & 1.63 & 0.64 & 0.01 & 2.66 & 0.91 \\
\hline
\end{tabular}


Table 2. Physical and mechanical properties of natural and recycled concrete aggregates.

\begin{tabular}{|c|c|c|c|c|c|c|c|c|}
\hline $\begin{array}{l}\text { Natural and } \\
\text { recycled } \\
\text { aggregates }\end{array}$ & $\begin{array}{l}\text { Oven-dried } \\
\text { particle density } \\
\left(\mathrm{kg} / \mathrm{dm}^{3}\right)\end{array}$ & $\begin{array}{c}\text { Water } \\
\text { absorption } \\
(\%)\end{array}$ & $\begin{array}{c}\text { Assessment of } \\
\text { fines. Sand } \\
\text { equivalent test (\%) }\end{array}$ & $\begin{array}{l}\text { Flakiness } \\
\text { index }(\%)\end{array}$ & $\begin{array}{l}\text { Crushing } \\
\text { value } \\
(\%)\end{array}$ & $\begin{array}{l}\text { LA } \\
\text { Index } \\
(\%)\end{array}$ & $\begin{array}{l}\text { Soluble } \\
\text { suphate } \\
\left(\% \mathrm{SO}_{3}\right)\end{array}$ & $\begin{array}{l}\text { Chloride } \\
\text { content } \\
\left(\% \mathrm{Cl}^{-}\right)\end{array}$ \\
\hline $\begin{array}{c}\text { River Sand } \\
0-2 \mathrm{~mm}\end{array}$ & 2.57 & 1.93 & 75.00 & & & & & \\
\hline $\begin{array}{c}\text { River Sand } \\
0-4 \mathrm{~mm}\end{array}$ & 2.50 & 1.02 & 87.88 & & & & & \\
\hline $\begin{array}{c}\text { River } \\
\text { Gravel } \\
\end{array}$ & 2.61 & 1.29 & & 17.71 & 18.92 & 19.61 & & \\
\hline $\begin{array}{c}\text { Dolomitic } \\
\mathrm{CA}\end{array}$ & 2.68 & 2.13 & & 7.81 & 20.15 & 24.77 & & \\
\hline RCA100 & 2.47 & 3.74 & & 16.53 & 22.59 & 24.01 & 0.43 & 0.02 \\
\hline RCA60 & 2.39 & 4.90 & & 13.57 & 23.36 & 25.24 & 0.52 & 0.01 \\
\hline RCA40 & 2.30 & 5.91 & & 9.59 & 25.55 & 24.31 & 0.45 & 0.02 \\
\hline
\end{tabular}

13 
Table 3. Proportioning of natural and recycled aggregate concretes.

\begin{tabular}{|c|c|c|c|c|c|c|c|c|c|}
\hline $\begin{array}{c}\text { Mix } \\
\text { notation }\end{array}$ & $\begin{array}{l}\text { Cement } \\
(\mathrm{kg})\end{array}$ & $\begin{array}{c}\text { Admixture } \\
(\mathrm{kg})\end{array}$ & $\begin{array}{c}\text { River Sand } \\
0-2 \mathrm{~mm} \\
(\mathrm{~kg})\end{array}$ & $\begin{array}{c}\text { River Sand } \\
0-4 \mathrm{~mm} \\
(\mathrm{~kg})\end{array}$ & $\begin{array}{c}\text { River } \\
\text { Gravel (kg) }\end{array}$ & $\begin{array}{l}\text { Dolomitic } \\
\text { Gravel } \\
(\mathrm{kg})\end{array}$ & $\begin{array}{l}\mathrm{RA} \\
(\mathrm{kg})\end{array}$ & $\begin{array}{c}\text { Total } \\
\text { Water } \\
(\mathrm{kg})\end{array}$ & $\begin{array}{c}\text { Effecttive } \\
\text { W/B }\end{array}$ \\
\hline NAC & 380 & 5.7 & 215.2 & 711.8 & 302.1 & 784.5 & - & 135.4 & 0.29 \\
\hline R100-50 & 380 & 5.7 & 215.2 & 711.8 & 151 & 392.2 & 505.1 & 146.5 & 0.29 \\
\hline R100-100 & 380 & 5.7 & 215.2 & 711.8 & - & - & 1010.2 & 162.3 & 0.29 \\
\hline R60-100 & 380 & 5.7 & 215.2 & 711.8 & - & - & 975.1 & 170.4 & 0.29 \\
\hline R40-20 & 380 & 5.7 & 215.2 & 711.8 & 241.6 & 627.6 & 187.8 & 139.7 & 0.29 \\
\hline R40-50 & 380 & 5.7 & 215.2 & 711.8 & 151 & 392.2 & 469.4 & 153.1 & 0.29 \\
\hline R40-100 & 380 & 5.7 & 215.2 & 711.8 & - & - & 938.8 & 175.3 & 0.29 \\
\hline
\end{tabular}

15 


\begin{tabular}{|c|c|c|c|c|c|c|c|}
\hline $\begin{array}{c}\text { Mix } \\
\text { notation }\end{array}$ & $\begin{array}{c}\text { Dry- } \\
\text { Density } \\
\left(\mathrm{kg} / \mathrm{dm}^{3}\right)\end{array}$ & $\begin{array}{c}\text { Absorption } \\
(\%)\end{array}$ & $\begin{array}{c}\text { Accessible Voids } \\
(\%)\end{array}$ & $\begin{array}{c}\text { 1-day } \\
\text { Compressive } \\
\text { strength } \\
(\mathrm{MPa})\end{array}$ & $\begin{array}{c}\text { 28-day } \\
\text { Compressive } \\
\text { strength (MPa) }\end{array}$ & $\begin{array}{c}\text { 90-day } \\
\text { Compressive } \\
\text { strength (MPa) }\end{array}$ & $\begin{array}{c}\text { Modulus } \\
\text { of } \\
\text { elasticity } \\
(\mathrm{GPa})\end{array}$ \\
\hline NAC & 2.51 & 1.39 & 3.49 & 66.83 & 100.05 & 111.64 & 50.41 \\
\hline R100-20 & 2.50 & 1.24 & 3.10 & 71.10 & 103.99 & 118.23 & 48.54 \\
\hline R100-50 & 2.48 & 1.51 & 3.72 & 64.59 & 102.42 & 116.86 & 47.93 \\
\hline R100-100 & 2.43 & 1.51 & 3.67 & 59.88 & 100.44 & 117.57 & 45.63 \\
\hline R60-20 & 2.44 & 1.76 & 4.44 & 72.09 & 104.10 & 116.89 & 47.79 \\
\hline R60-50 & 2.40 & 1.93 & 4.64 & 67.14 & 102.17 & 114.28 & 44.28 \\
\hline R60-100 & 2.34 & 2.43 & 5.69 & 65.76 & 91.22 & 101.36 & 40.09 \\
\hline R40-20 & 2.47 & 2.08 & 5.14 & 71.98 & 102.80 & 115.27 & 48.29 \\
\hline R40-50 & 2.43 & 2.12 & 5.16 & 63.39 & 101.94 & 113.45 & 43.04 \\
\hline R40-100 & 2.39 & 2.17 & 5.20 & 61.36 & 89.03 & 99.86 & 37.15 \\
\hline
\end{tabular}

18 
Table 5. Porosity and average pore diameter from MIP test of natural aggregate concrete (NAC) and recycled aggregate concretes containing $100 \%$ of RCA100, RCA60 and RCA40 at the ages of 1, 28 and 90 days.

22

\begin{tabular}{|c|c|c|c|c|c|c|}
\hline Mix notation & \multicolumn{3}{|c|}{ Porosity (\%) } & \multicolumn{3}{c|}{ Average Pore Diameter $(\mu \mathrm{m})$} \\
\hline & 1 day & 28 days & 90 days & 1 day & 28 days & 90 days \\
\hline NAC & 7.30 & 5.52 & 5.19 & 0.054 & 0.045 & 0.033 \\
\hline R100-100 & 6.31 & 6.11 & 4.78 & 0.050 & 0.048 & 0.038 \\
\hline R60-100 & 9.29 & 6.58 & 5.31 & 0.060 & 0.050 & 0.036 \\
\hline R40-100 & 9.67 & 8.28 & 6.92 & 0.063 & 0.055 & 0.040 \\
\hline
\end{tabular}




\section{Figures:}

$2 \quad$ Fig. 1. Plastic shrinkage test specimen and setup.

3 Fig. 2. Pore size cumulative distribution of natural aggregate concrete (NAC) and recycled aggregate

4 concretes containing $100 \%$ of RCA100, RCA60 and RCA 40 at the ages of 1 (a), 28 (b) and 90 days (c).

5 Fig. 3. Plastic shrinkage of natural aggregate concrete (NAC) and recycled aggregate concretes containing 6 RCA100 (a), RCA60 (b) and RCA 40 (c).

7 Fig. 4. Autogenous shrinkage of natural aggregate concrete (NAC) and recycled aggregate concretes containing RCA100 (a), RCA60 (b) and RCA 40 (c).

9 Fig. 5. Drying shrinkage of natural aggregate concrete (NAC) and recycled aggregate concretes containing RCA100 (a), RCA60 (b) and RCA 40 (c).

11 Fig. 6. Relationship between RCA replacement ratio and maximum drying shrinkage strain of RAC.

12 Fig. 7. Mass loss due to drying conditions of natural aggregate concrete (NAC) and recycled aggregate 13 concretes containing RCA100 (a), RCA60 (b) and RCA 40 (c).

14 Fig. 8. Relationship between relative modulus of elasticity and drying shrinkage strain of RAC at 28a 15 days. 


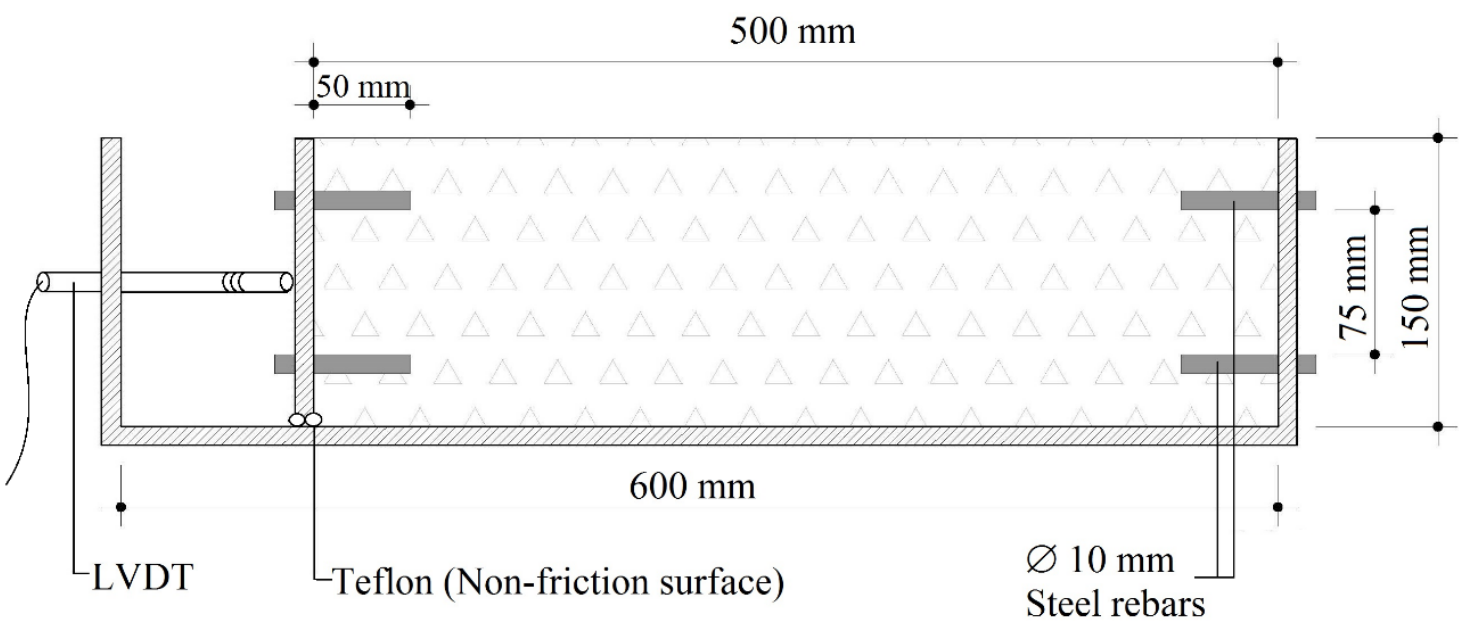

20

Fig. 1. Plastic shrinkage test specimen and setup.

21 


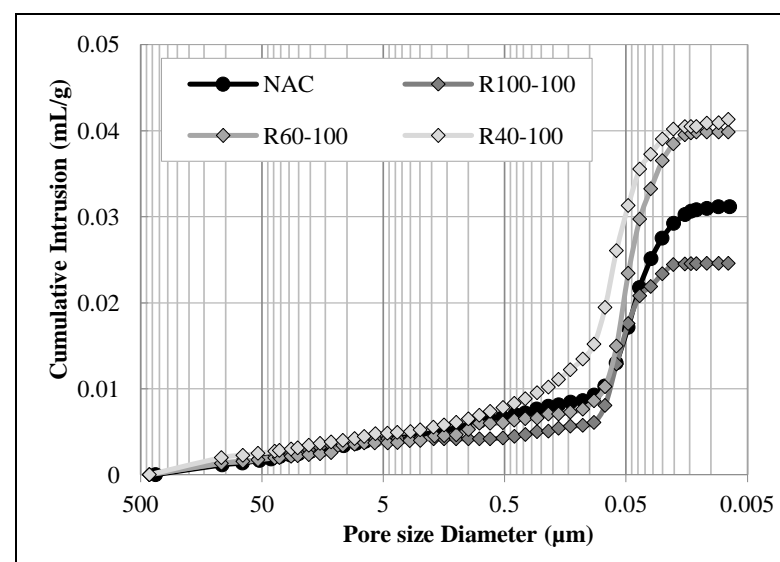

(a)

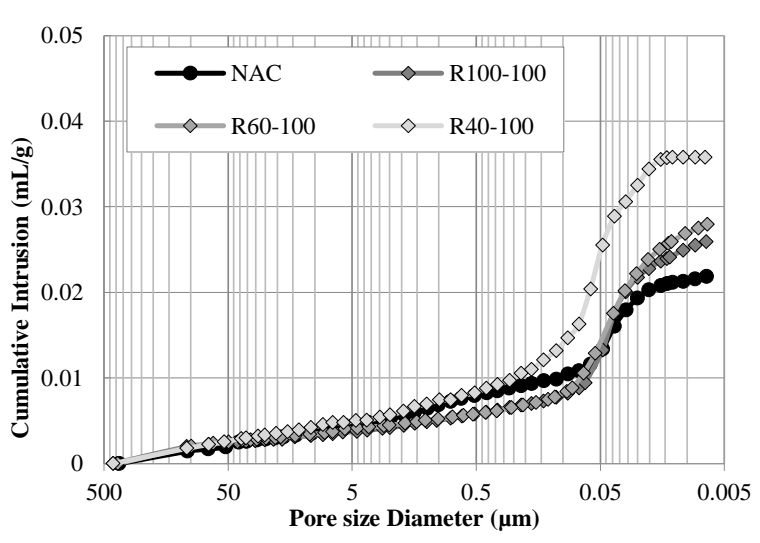

(b)

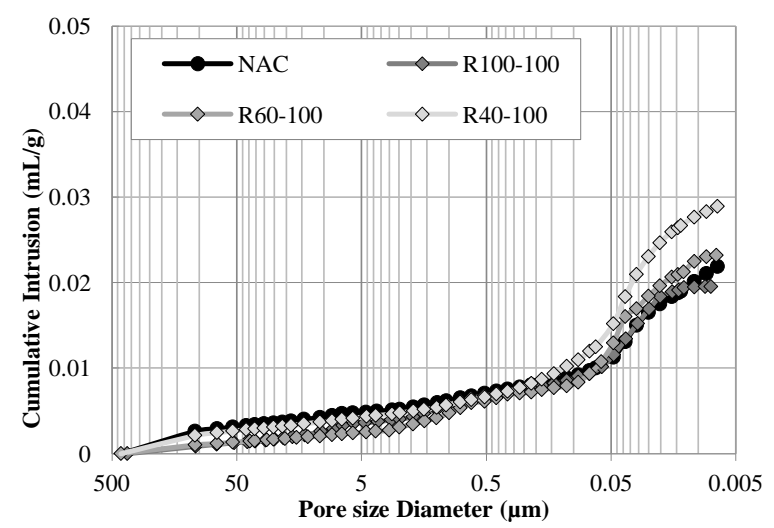

(c)

Fig. 2. Pore size cumulative distribution of natural aggregate concrete (NAC) and recycled aggregate concretes containing $100 \%$ of RCA100, RCA60 and RCA 40 at the ages of 1 (a), 28 (b) and 90 days (c) 


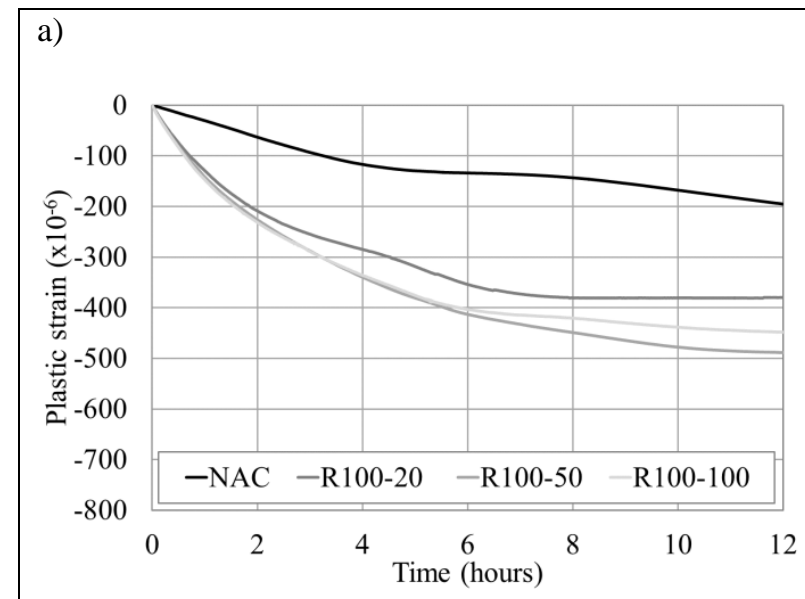

b)

c)

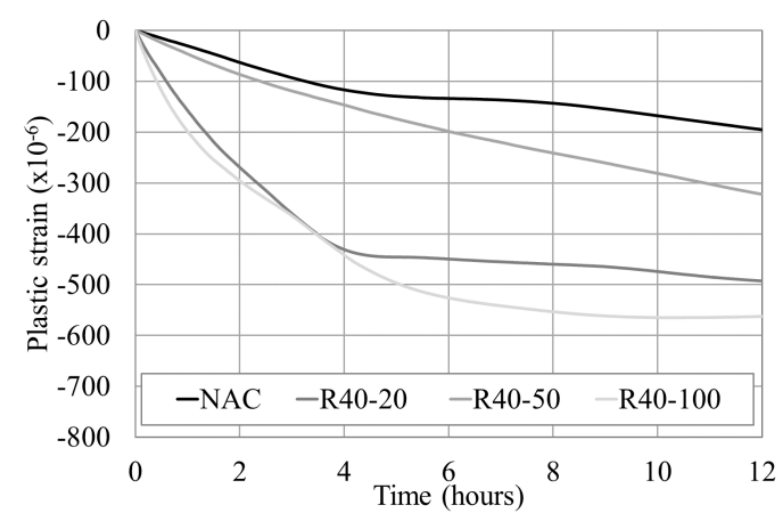

26 Fig. 3. Plastic shrinkage of natural aggregate concrete (NAC) and recycled aggregate concretes containing RCA100 (a), RCA60 (b) 27 and RCA 40 (c). 


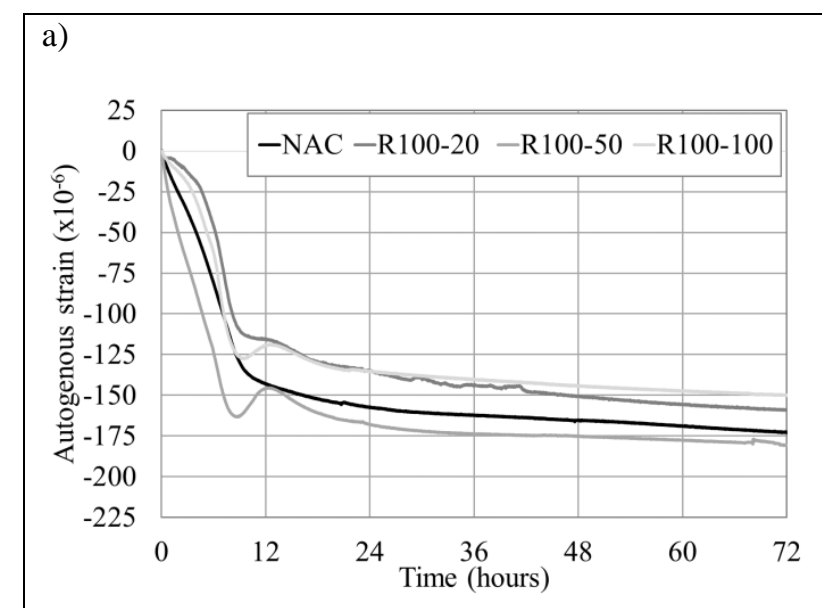

b)

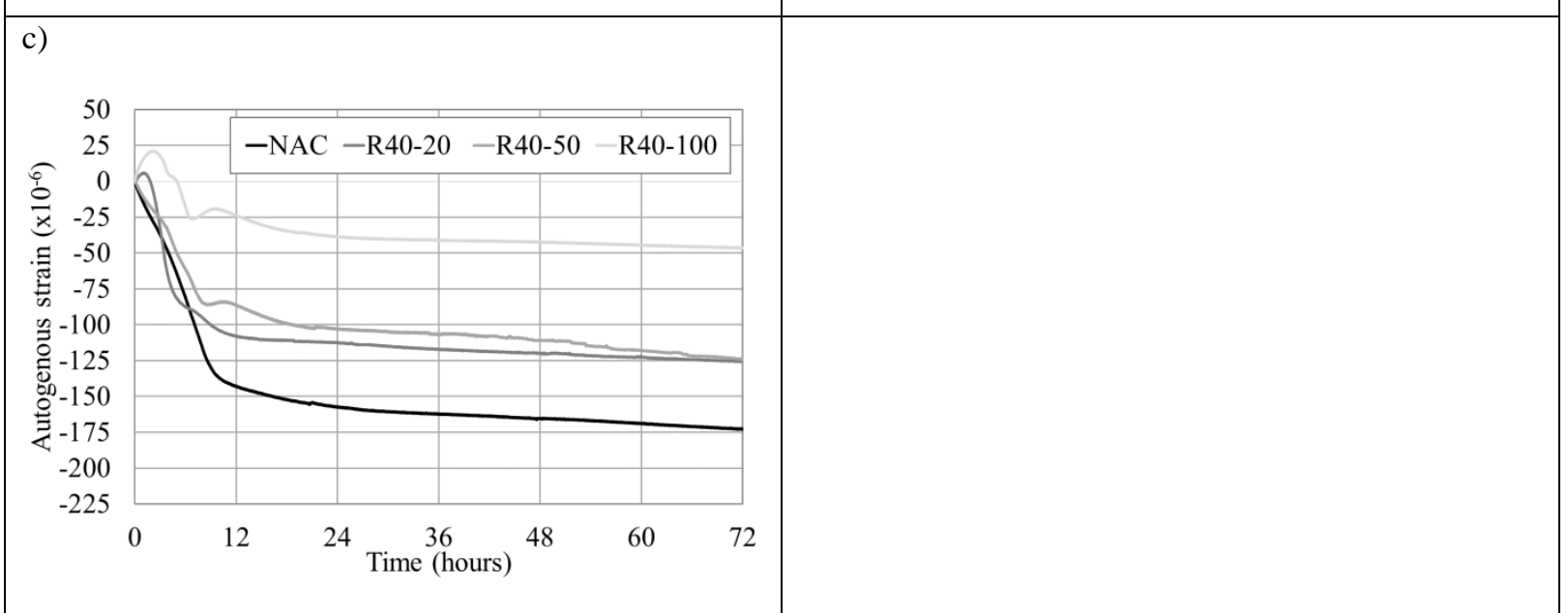

30 Fig. 4. Autogenous shrinkage of natural aggregate concrete (NAC) and recycled aggregate concretes containing RCA100 (a),

$31 \quad$ RCA60 (b) and RCA 40 (c). 


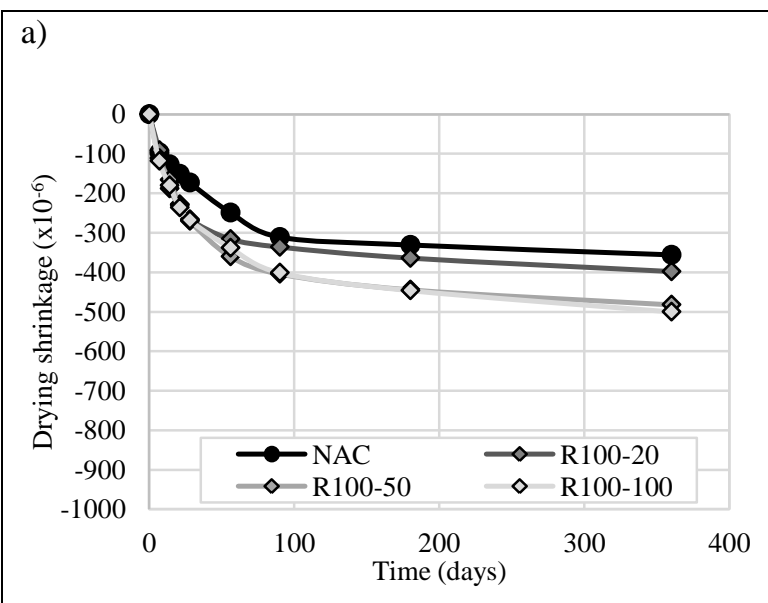

b)

c)

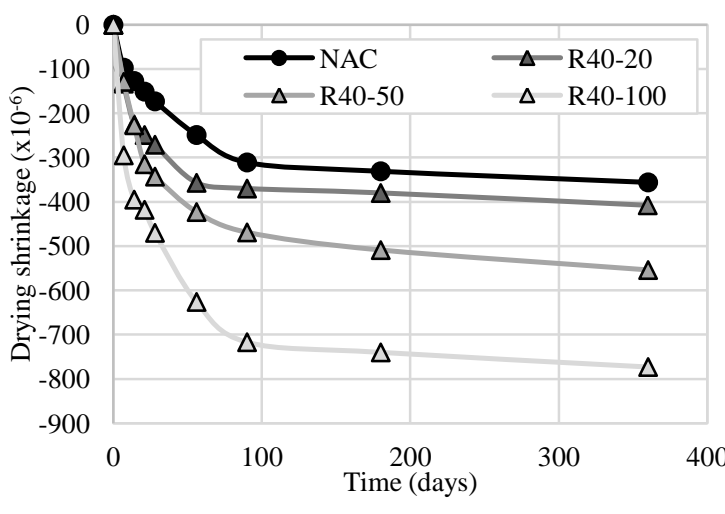

Fig. 5. Drying shrinkage of natural aggregate concrete (NAC) and recycled aggregate concretes containing RCA100 (a), RCA60 (b) and RCA 40 (c). 


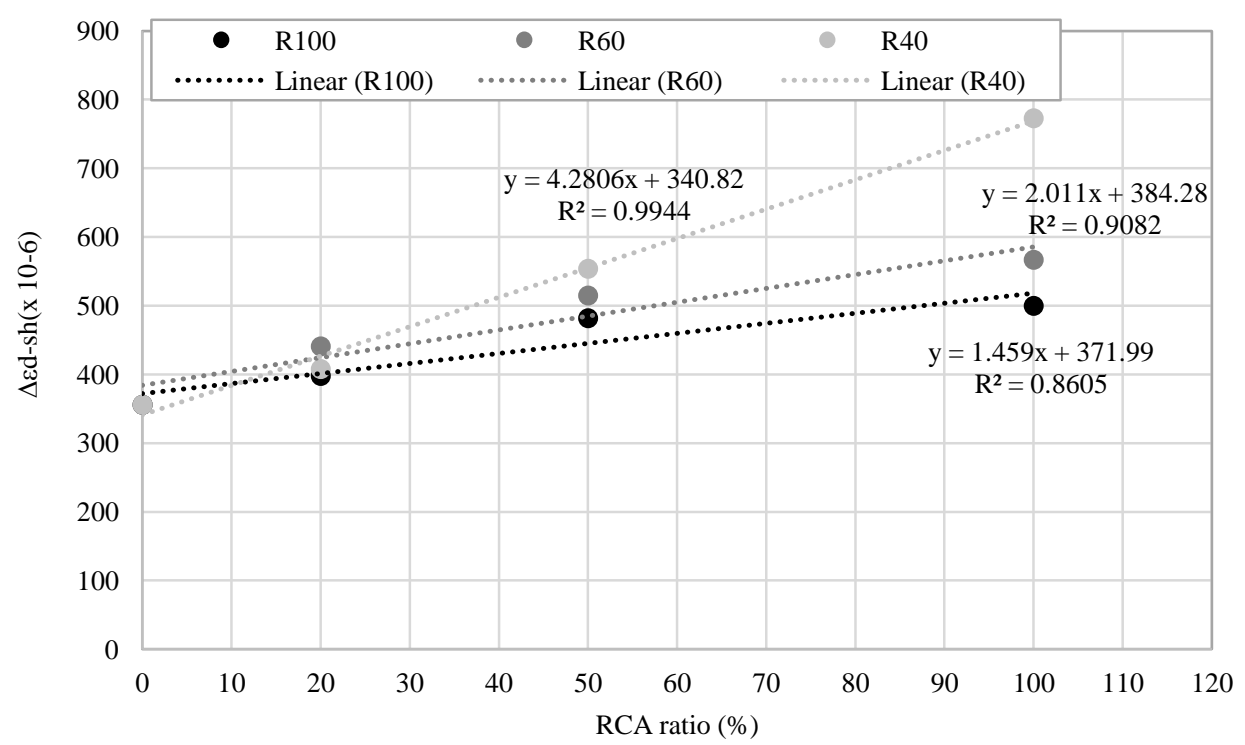

Fig. 6. Relationship between RCA replacement ratio and maximum drying shrinkage strain of RAC. 


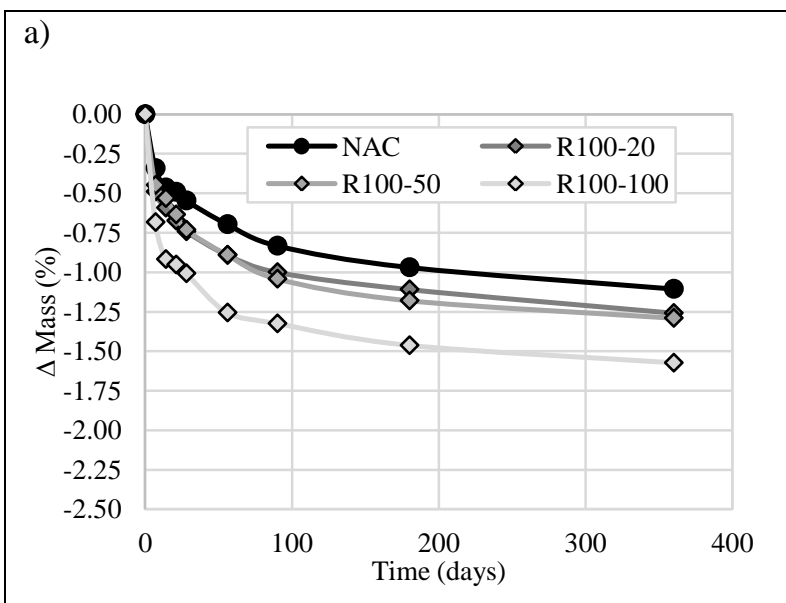

b)

c)
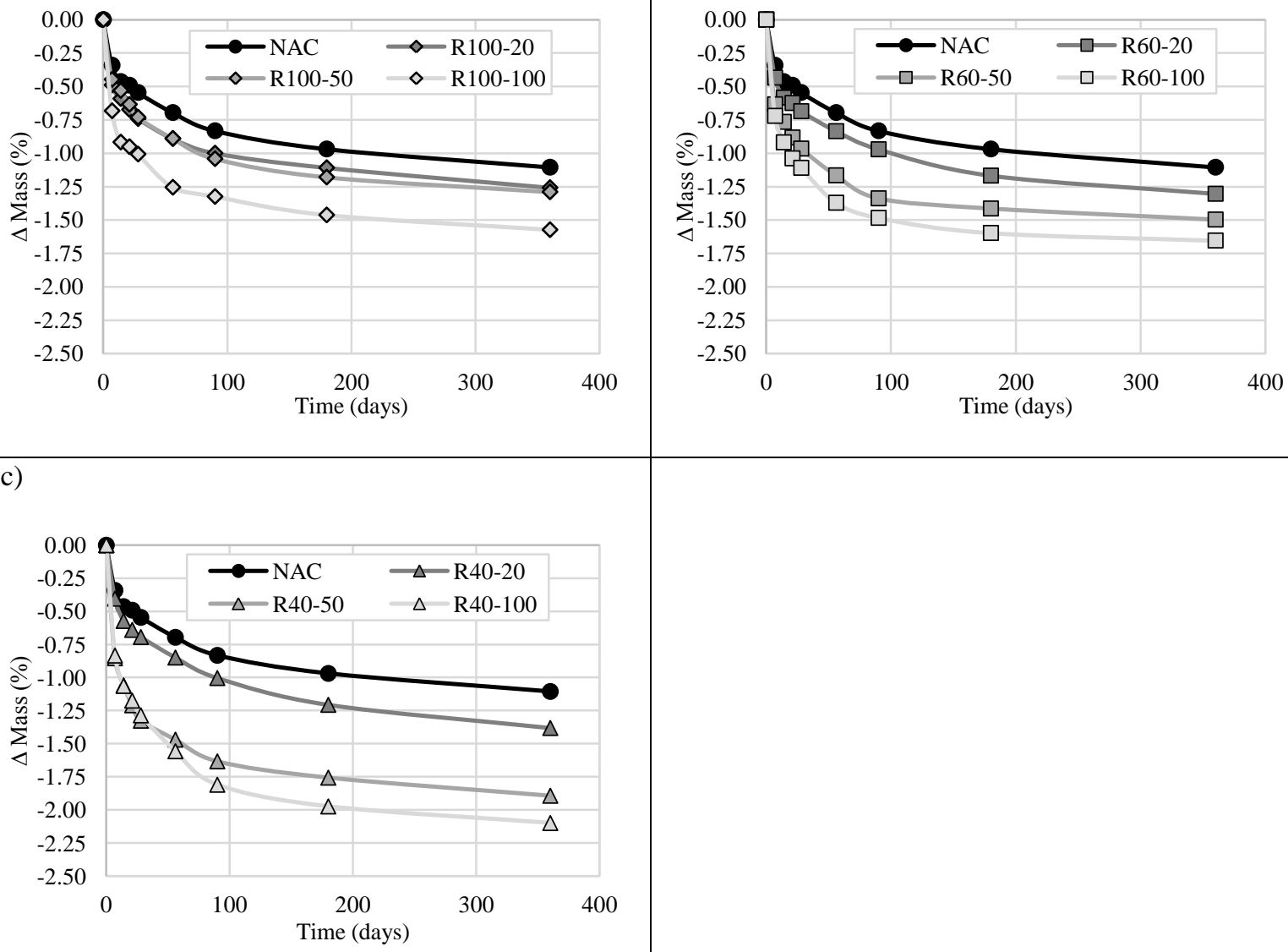

Fig. 7. Mass loss due to drying conditions of natural aggregate concrete (NAC) and recycled aggregate concretes containing RCA100 (a), RCA60 (b) and RCA 40 (c). 


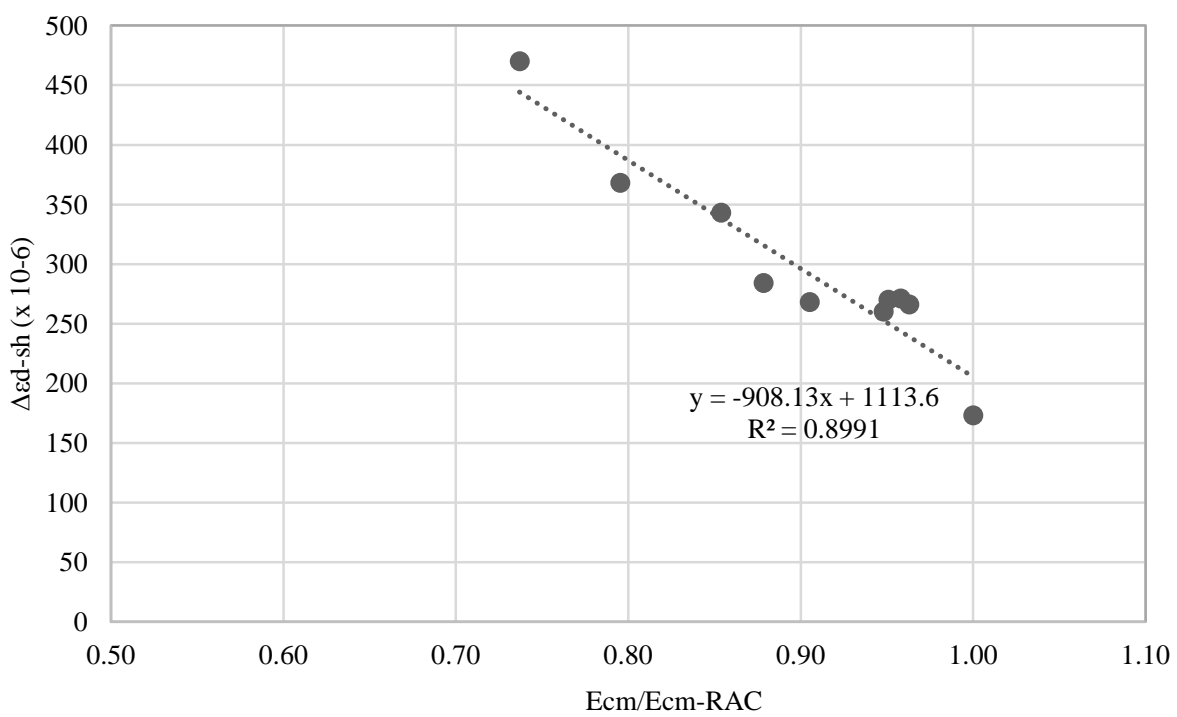

Fig. 8. Relationship between relative modulus of elasticity and drying shrinkage strain of RAC at 28a days. 